\title{
Zur Zweigliederung der südbayerischen Würmeiszeit durch eine Innerwürm-Verwitterungsperiode
}

\author{
Von E. Kraus, München. \\ Unter Mitverwendung eingehender Geländeuntersuchungen und -beschreibungen bei Murnau \\ durch Dr. R. LeBKüchNer, Ankara. \\ Mit 12 Abbildungen.
}

\begin{abstract}
$\mathrm{Zusammenfassung.} \mathrm{Die} \mathrm{Arbeit} \mathrm{bringt} \mathrm{den} \mathrm{Nachweis} \mathrm{einer} \mathrm{Zweigliederung} \mathrm{des} \mathrm{Würm-}$ eiszeit-Klimas durch Feststellung eines innerwürmischen Verwitterungsbodens. Dieser läßt schließen auf eine mehrere Jahrtausende umfassende interstadiale Klimaschwankung von subarktischem Charakter zwischen den großen Eisausbreitungen einer "Altwürmzeit" und einer "Jungwürmzeit “ im Alpenvorland; dies zunächst einmal für den Bereich der weiteren Umgebung von Murnau im Loisach- und im Ammersee-Gletschergebiet. Die bisher unbekannt gebliebene Verwitterungsrinde kann in zahlreichen Gruben des altwürmischen Murnauer Schotters beobachtet werden. Sie ist unmittelbar überlagert von der Grundmoräne des letzten großen Würmeis-Vorstoßes. Einige Anhaltspunkte für weitere Folgen dieser innerwürmischen Klimaschwankung können bereits angeführt werden. Auf dem Laufenschotter ist ein Verwitterungsboden entsprechenden Alters (noch?) nicht bekannt.

Rés u mé. On a beaucoup discuté sur la possibilité d'une bipartition de l'époque glaciale dernière, dite Würm-Eiszeit. C'est au Nord du Murnau ( $55 \mathrm{Km}$ SSO de Munich) que l'auteur, dans 12 gravières, trouvait un sol fossil au-dessus du gravier de l'époque wurmienne plus ancienne et au-dessous de la moraine dernière. Voilà l'argument pour la bipartition de l'époque wurmienne en Bavière.
\end{abstract}

\section{Vorwort}

Gelegentlich angewandtgeologischer Aufgaben, verbunden mit 11/2jähriger, intensiver Geländearbeit von Dr. R. LEBKüCHNER zwischen dem Hechendorfer Loisachknie im S und Gauting im N, sowie von Dr. W. S. Buchardt im Loisachquertal unterhalb von Oberau, wurde unter Leitung des Verfassers eine vollständige Diluvialprofil-Zone von den Alpen bis in die Münchener Ebene hinaus erarbeitet. Ưber den im Gelände hauptsächlich durch Dr. R. LEBküCHNER untersuchten Abschnitt vom Murnauer Moos bis Weilheim wird hier kurz berichtet.

Den Wasserwerken der Stadt München, namentlich auch Herrn Oberbaurat Dr. Sснмidт, darf ich für die verständnisvolle Einschaltung der geologischen Arbeit in die praktische Planung, für die große Förderung und die Erlaubnis einer Veröffentlichung der wissenschaftlichen Ergebnisse bestens danken. Ebenso danke ich Herrn Regierungsdirektor Dr. H. AnNDT für die Erlaubnis, meine Bodenproben im Laboratorium des Payer. Geolog. Landesamts untersuchen zu lassen. Herr Dr. Abele hat diese Untersuchung in dankenswerter Weise durchgeführt.

\section{Einleitung}

Es mehren sich in den letzten Jahren die Beobachtungen, welche dafür sprechen, daß die südbayerische Würmeiszeit zweigeteilt war. Im Anschluß an B. EBERL in Schwaben 1930 hat dies wohl zuerst J. KNAUER 1935 (sehr kurzes Interstadial) und 1937 (längeres Interstadial) betont, dann J. SchaEfer 1940 (für längeres Interstadial) entgegen einer ungegliederten Würmeiszeit (A. PENCK, E. BRÜCKNER u. a.) oder einer dreigeteilten (B. EBerL 1924, 1930). C. Rathjens unterstützte 1951 die Zweigliederung auf Grund von Ergebnissen im Rheingletscherbereich und von P. BECK in der Schweiz.

Die beiden bisher für diese Zweiteilung von J. KNAUER (1937) bei Brandach am Peißenberg-Südhang ( $r$ ot-brauner Boden!) und von A. Micheler (1948) bei Ob im 
Lechgletschergebiet ( $\mathrm{mächtige} \mathrm{Verwitterung!)} \mathrm{beigebrachten} \mathrm{Anhaltspunkte} \mathrm{sind}$ aber nicht unwidersprochen geblieben. Denn zwar ist diesen Böden eine Jungmoräne aufgesetzt. Aber das würm- oder rißeiszeitliche Alter der hier verwitterten Unterlagen steht nicht fest.

Ebensowenig konnte die durch B. EBERL und J. KNAUER aus der Uberfahrung der W I-Endmoräne durch die W II-Moräne gefolgerte regionale Zweiteilung bisher allgemeine Zustimmung finden. J. BüdeL $(1936,1950)$ und C. Troll (in mehreren Arbeiten) sehen diese Überfahrung nicht an als eine regionale Erscheinung, sondern als Folge lokaler Eisrand-Oszillationen. - Die Auelehm- bzw. Lößdecke auf I. Schaefer's W INiederterrassenfeld von Memmingen-Fellheim-Weißenhorn wäre kein Verwitterungsboden, sondern ein später aufgeschüttetes Sediment (K. BRunNacker 1953). Der Löß könnte eine vielleicht spätwürmisch noch aufgeblasene Ablagerung sein. H. GrauL hält auf Grund eingehender Geländearbeiten im Iller- und Rheingletscherraum die SCHAErER'sche Zweigliederung an Stelle einer einheitlichen Würmeiszeit nicht für richtig, und manche Stimmen pflichten ihm bei. Einem W-III-Stadium wird von den Beobachtern nicht zugestimmt:

Gelegentlich ausgedehnter Geländebeobachtungen im Zusammenhang mit anderen Fragen konnte ich bisher für die Aufgliederung des A. Penck'schen Diluvialsystems im Einklang mit der anziehend-exakten Klimakurve von Milankovic keine sicheren Beobachtungen sammeln. Erst mehrfache Begehungen im Salzachgletschergebiet unter freundlicher Führung durch E. EBERS oder im Rheingletscherbereich durch Fr. WEIDENВACH brachten feste Anhaltspunkte für eine gewisse Untergliederung der Rißeiszeit.

Die zwischen dem Loisachquertal und Gauting ausgedehnten Geländearbeiten (R. LebküChNER) für hydrogeologische Zwecke schienen aber eine Gliederung der Würmeiszeit wieder nicht zu bestätigen. Jedoch gelang es mir dabei, über dem Murnauer Schotter und unter der obersten Grundmoräne in 12 gut aufgeschlossenen Kiesgruben einen Verwitterungshorizont zu entdecken. Er ist innerhalb des Würmdiluviums, also „innerwürmisch“ weit verbreitet und wurde Anlaß zu vorliegender Arbeit. Statt der. in Kontroversen allmählich unklar gewordenen Begriffe "W I-III" unterscheide ich im Folgenden:

3) eine Jungwürm-Zeit mit dem letzten Hauptvorstoß der Würmeiszeit,

2) eine Innerwürm-Zeit, in unserem Arbeitsgebiet eisfrei,

1) eine Altwürm-Zeit mit dem ersten Hauptvorstoß der Würmeiszeit.

Wenn der Innerwürmboden bislang von A. Penck, D. Aigner, Aug. Rothpletz, J. Knauer, C. Troll und anderen Bearbeitern unseres Gebietes nicht erkannt wurde, so kann dies aus mehrfachen Gründen verstanden werden. Kiesgruben legt roan tekanntlich meist nur dort an, wo schon zunächst der Erdoberfläche ein brauchbarer Kies ansteht. Darum ist es unwahrscheinlich, daß sich Gruben an Stellen befinden, die einen für die Praxis ungeeigneten, alten Verwitterungsboden über dem Kies von einiger Mächtigkeit zeigen. Besonders interessant wird erdgeschichtlich für uns ein Verivitterungshorizont erst dann, wenn sein vorjüngst-würmeiszeitliches Alter durch Überlagerung mit ausgedehnter Moräne erweisbar ist. Diese ist im fraglichen Gebiet als Grundmoräne (Geschiebemergel) ausgebildet, also so gut wie unbrauchbar für technische Zwecke. Nur dann besteht die Aussicht, unsere Profile aufgeschlossen zu bekommen, wenn sich seitwärts von dem zutage tretenden, guten Kies nach Vertiefung und Erweiterung der Kiesgrube allmählich die Altboden- und Moränen-Überlagerung einstellte. Solcher mächtiger werdender und daher für die Praxis hinderlicher Abraum führt dann verständlicherweise, aber leider, zum Auflassen dieser Kiesgruben. Nachfolgend wird unser bedeutungsvoller Verwitterungs-Horizont über dem Murnauer Schotter näher untersucht. 


\section{Definition des Murnauer Schotters („Mu.Sch.“)}

Dieser Schotter wurde wechselvoll beurteilt. 1882 hatte ihn A. PENCK allen losen Schottern, welche die Jungmoräne unterteufen, also den frühglazialen „unteren Glazialschottern" zugeordnet. 1902 versetzte er die Mu.Sch. in die "Nachwürmzeit" des Bühlvorstoßes, obwohl sie noch von Moräne überlagert werden. Nach Ablehnung dieses Vorstoß-Stadiums durch D. Aigner (1913) definierte Aug. Rothpletz (1917, S. 56) den Mu.Sch.: „Alter als die Jungmoräne und jünger als interglaziale Schichten“. Er sei eine "Rückzugserscheinung des Würmgletschers". 1922 und nachfolgend kehrte auch A. PENCK allmählich zu seiner Ansicht von 1882 zurïck. C. Troll (1937, S. 603) u. a. sehen in unserem Schotter einen älteren Würmschotter der Anrückungszeit.

Doch wird sich auch diese Definition noch differenzieren müssen. Denn als e in he it 1 ich e r Entstehung können wohl nur die oberen Teile dieses Schotters mit seiner sehr typischen Terrassenebenheit gelten, welche das sanft gegen $\mathrm{N}$ abgedachte Landschafts-Relief zur Hauptsache noch heute beherrscht. Abgesehen von der mehr oder weniger dünnen Grundmoräne über dem Mu.Sch. sind aufgesetzt die Wallhügel der oft schotterigen Moräne des letzten Würmeis-Rückzuges. Diese Hügel schließen sich örtlich zusammen zu jungwelligen Landformen, welche jedoch wegen ihrer zumeist wenig verschiedenen und geringen Mächtigkeit noch immer ihre ebene Unterlage zu erkennen geben.

Weil unser Verwitterungshorizont zwischen Grundmoräne und Mu.Sch. liegt, kann letzterer nicht, wie man entgegen Aug. RothPLETz wohl allgemein annahm, ein Anrückungs- oder Vorstoß-Schotter des letzten Jungwürmeises sein, das anschließend seine Grundmoräne dem Mu.Sch. unmittelbar aufgelegt hat. E in e längere, e is f rei e $Z_{w}$ ischenzeit derinnerwürmischen Verwitterung mu also eingeschaltet gewesen sein zwischen Schotterausbreitung.und letztem Würmeis-Vorstoß. Es gilt dies jedenfalls für den etwa $15 \mathrm{~m}$ mächtig in den Kiesgruben aufgeschlossenen $\mathrm{Hangendteil}$ des etwa $40 \mathrm{~m}$ mächtigen Mu.Sch.

Aber ebenso wie z. B. der Niederterrassenschotter der Münchener Ebene nach sehr zahlreichen neuen Bohrungen über verschiedene ältere Schotter, Nagelfluhen, Moränen und über Flinz zunächst vorgeschüttet wurde und keine Rückzugsmoräne mehr ihn überlagert, so kann man auch nicht ohne weiteres annehmen, daß a uch di e tief er e n Schotterteile des Mu.Sch. einem Eisrückzug entsprechen. Sehr wohl können diese im Sinn von C. TrolL etwa einem Vorstoß und Stillstand des alpinen Eisrandes weiter im S entstammen und nur hangende Schotterteile einer Rückzugszeit. Die Führung oder das Fehlen zentralalpiner Gerölle kann hierbei als weiteres Argument dienen.

Damit sind einige Probleme formuliert, die, im absichtlich eng gehaltenen Rahmen, teilweise noch keine endgültige Beantwortung finden, die wegen ihrer Bedeutung jedoch nicht zu umgehen sind.

\section{Der Ausklang der Letztinterglazialzeit}

Die Bedeutung der Verbreitung kristalliner Gerölle. Im Gegensatz zu den tieferen, an Kristallingeröll noch so gut wie freien Schottern zeigt sich bei Großweil (Abb. 1) alsbald über der bekannten Schieferkohle, bei Schwaiganger im W etwas später, eine zunehmende Anlieferung auch von Kristallingeröll aus den rückwärtigen Gebirgstälern. Diese reichliche zentralalpine Belieferung bleibt sodann bezeichnend für die Mu.Sch., also für die Altwürmschotter.

Zum wenigsten die beiden letzten Diluvialsysteme der Riß- und der Würmzeit lassen bekanntlich mit dem Fortschreiten ihrer Eisverbreitung erst allmählich auch in ihren Schotterausstrahlungen die Ankunft erheblicher Geröllmengen aus den Zentralalpen erkennen. Damit bildeten sich also Anfangsstadien einer Großvereisung ab. 


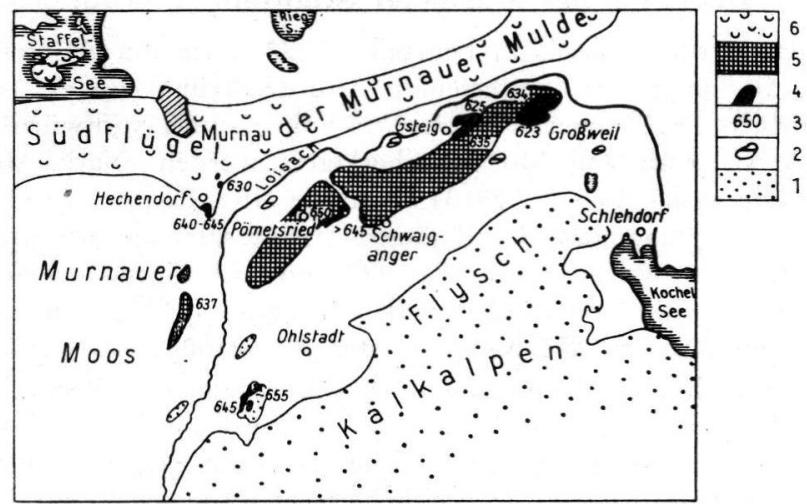

Abb. 1. Skizze der Vorkommen von Interglazial (Schieferkohle und Pelit) zwischen Ohlstadt und Großweil. 1 Kreideflysch, Kalkalpen. 2 Helvetische Kreide im Osten. 3 Höhenlage des Interglazials. 4 Ausstriche von Interglazial. 5 Diluvialer Schotter, z. T. Nagelfluh. 6 Molasse.

Ein klares Beispiel a u ch für die Abbildung des Schluß-Stadiums einer Großvereisung durch die Führung kristalliner Gerölle bzw. durch deren Aufhören im fluvioglazialen Schotter nach oben, kann für unser Nordrandgebiet der Alpen aus dem Schotter des Loisachquertales unterhalb von Garmisch angeführt werden. Hier wurden im Zusammenhang mit praktischen Fragen bisher ca. 25 Bohrungen, eine bis zu 155,7 m Tiefe, unterhalb von Oberau in regelmäßiger Verteilung über den Talboden niedergebracht. Mit G. $\mathrm{H}_{\mathrm{ABER}}$ beobachtete ich die Ergebnisse und stellte folgende, sehr überraschende Regelmäßigkeit fest: Unter dem durch Moor- und Schlick-Zwischenlagen, sowie durch raschen Sedimentwechsel ausgezeichneten Talalluvium liegen hier bis durchschnittlich fast genau $30 \mathrm{~m}$ tief durchweg Karbonatschotter oh n e im Bohrgut erkennbare Kristallingerölle. Erst darunter setzt dann a us a hmslos eine reichliche Kristallingeröllführung bzw. Feldspatsandführung des Würmschotters ein. Der Hangendkies ohne Kristallin dürfte jener Zeit angehören, in welcher keine glaziale Zulieferung aus den Zentralalpen mehr erfolgt war. Während dieser Jungwürmzeit, in die vielleicht die Schmelzwasserbelebung durch O. AMpFERER's Schlußvereisung im Gebirge noch fiel, kamen die Schmelzwässer nur noch aus Gletschergebieten der nördlichen Kalkalpen in unseren Bereich. Es scheint also, daß sich bei ausreichender Beobachtungsmöglichkeit am Kalkalpenrand, besonders auch an gut beobachteten Bohrungen, Kennzeichen für das An- und Abschwellen zunächst einmal der würmeiszeitlichen Eismassen ergeben.

Die Lagedes Letztinterglazials von Großweil-Ohlstadt. Innerhalb der Liegendschotter der Warmserie von Großweil-Ohlstadt gab J. KNAUER (1922, S. 55 und Fig. 5) für Großweil eine Schottermoräne an, ïber deren KristallinGehalt nichts bekannt ist. Im ganzen Arbeitsgebiet fehlt jeder Rest des bekanntlich tiefgreifenden und intensiv blutlehmigen Bodens der Interglazialen Hoch-Zeit, auch jede Spur verschwemmter rotlehmiger Bodenreste. Zwischen der Warmserie und dem ihr folgenden altwürmischen Mu.Sch. konnte keine Moräne nachgewiesen werden. Aber über der Warmserie setzt sogleich der Mu.Sch. mit reichlich Kristallingeröllen ein. D a s spricht schon für den Hauptrorstoß des zentralalpinen Gebirgseises - wenn auch noch nicht bis Großweil, wo die Moräne noch fehlt.

Die eisfreie Serie von Großweil hat man mit Recht noch in das Riß/Würm-Interglazial gestellt (R. DEнм 1937, H. REICH 1953). Der Mangel an einer thermophilen, gegenüber dem heutigen wärmeres Klima bezeugenden Flora, auch an Roterde kann in diesen nichtmarinen Horizonten, die nur so lïckenvoll abgelagert wurden und noch 
viel lückenhafter erhalten blieben, so verstanden werden, $\mathrm{da} B$ a be r a $11 \mathrm{e}$ in $\mathrm{die}$ $S p a ̈ t z e i t$ dieses Letztinterglazials dort vertreten ist. Dies würde übereinstimmen sowohl mit dem erst nach Ablagerung der eisfreien Serie erfolgenden Einsetzen der später zur Würmhauptzeit so bezeichnenden Kristallingerölle unseres Gletschergebietes. Es stimmt ebenso gut mit den vegetationsgeschichtlichen Ergebnissen von H. REICH. Diese zeigte, daß nach der Eichenmischwald- und Hainbuchen-Tannenzeit des heutzeitlichen Klimas unter Feuchterwerden ein moorbildendes, subarktisches und dann ein frühglaziales Klima floristisch zur Abbildung kam. Dadurch wurden die Vegetationsstufen-Höhen zunächst um $600 \mathrm{~m}$, dann um zusammen $1000 \mathrm{~m} \mathrm{MH}$. herabgedrückt. Ahnlich tief wird sich auch die Schneegrenze abgesenkt haben und während der Bildungszeit des ersten Würmeises allmählich dem Alpenrand nähergerückt sein.

Die eisfreie Serie von Großweil-Ohlstadt entstand somit gegendas Endeder letzten Interglazialzeit, unmittelbar bevor sich der erstezentralalpine $\mathrm{Haupteis}$ a orstoß der Wiirmeiszeit a uszuprägen begann.

\section{Der Murnauer Schotter (Aug. Rothpletz 1917), ein Altwürmschotter}

Eigenschaften. Der Mu.Sch., der nach den Aufschlüssen von Großweil also unmittelbar der besprochenen Übergangsserie folgt, hat ein frischgraues, also unverwittertes Aussehen. Seine Gerölle sind immer gut abgerundet, von meist mittlerer Durchschnittsgröße, nur gelegentlich über kopfgroß; sie gehen in Sandbänke über. Recht bezeichnend ist die großzügig-gleichmäßige Ausbildung weithin durch alle Kiesgruben, die in den hangenden 20 Metern angelegt sind. Die regelmäßige Flachschichtung geht nicht oft über in stärker geneigte Schrägschichtung der Bänke.

Im Gegensatz zum Niederterrassenschotter sind die Gerölle des Mu.Sch. recht regelmäßig mit etwas Kalzit verkrustet, was deren gegenseitige Reibung vermehrte, trotzdem sie meist noch lose nebeneinanderliegen. Daher sind die Kiesgruben regelmäßig mit steileren Böschungen versehen und für den Abbau gefährlicher als jene des Niederterrassenschotters. O'rtlich, besonders an Talhängen, kommt es auch zu einer, wenn auch porenreichen Nagelfluh-Verkittung. Doch ist das erheblich seltener der Fall und betrifft weniger die Einzelbänke wie in der Hochterrasse.

Bei Etting (im $\mathrm{N}$ der Karte, Abb. 2) steht noch der Murnauer Schotter an. Hier hat man unlängst einen Mammutzahn gefunden; andere bestimmbare Funde wurden bisher nicht bekannt.

Man wird wohl erwarten können, daß die gegenüber dem Jungwürmschotter eindeutig stärkere Durchkrustung zurückzuführen ist auf die längerdauernde, zusätzliche Durchsickerung mit kalkführendem Verwitterungswasser, hervorgerufen d u r ch die innerw ürmische Verwitterung des Mu.Sch. Dabei und nachher dürfte der Grundwasserspiegel, über dem die Krusten sich ansiedelten, allmählich abgesunken sein. L. SIMON brachte 1935 über die Konglomerierung des Laufenschotters, der altersmäßig und wohl auch genetisch unserem Mu.Sch. zu entsprechen scheint, gutc Beobachtungen. Daß die Stärke der Konglomerierung $u$. a. abhängig ist von der Intensität und Dauer der darüber ehemals stattfindenden Verwitterung, also der hierbei freiwerdenden und absinkenden kalkhaltigen Lösungen, das kann angenommen werden.

Allein in südlichsten Kiesgruben des Mu.Sch. können Merkmale einer zunehmenden Eisnähe beobachtet werden. Die von A. PENCK 1901 (vgl. 1922, 223) mitgeteilte Einlagerung von Moräne in einer alten Kiesgrube des Mu.Sch. nördlich Bahnhof Murnau war später, auch von uns, nicht mehr zu beobachten. Mitunter fanden sich an den teilweise kopfgroßen Geröllen in der großen Grube sö. bei Bahnhof Murnau glaziale Kritzer, ebenso hinter dem Gut Schwaiganger in etwas tieferem Schotterniveau an z. T. nur kantenrunden Geschieben. 


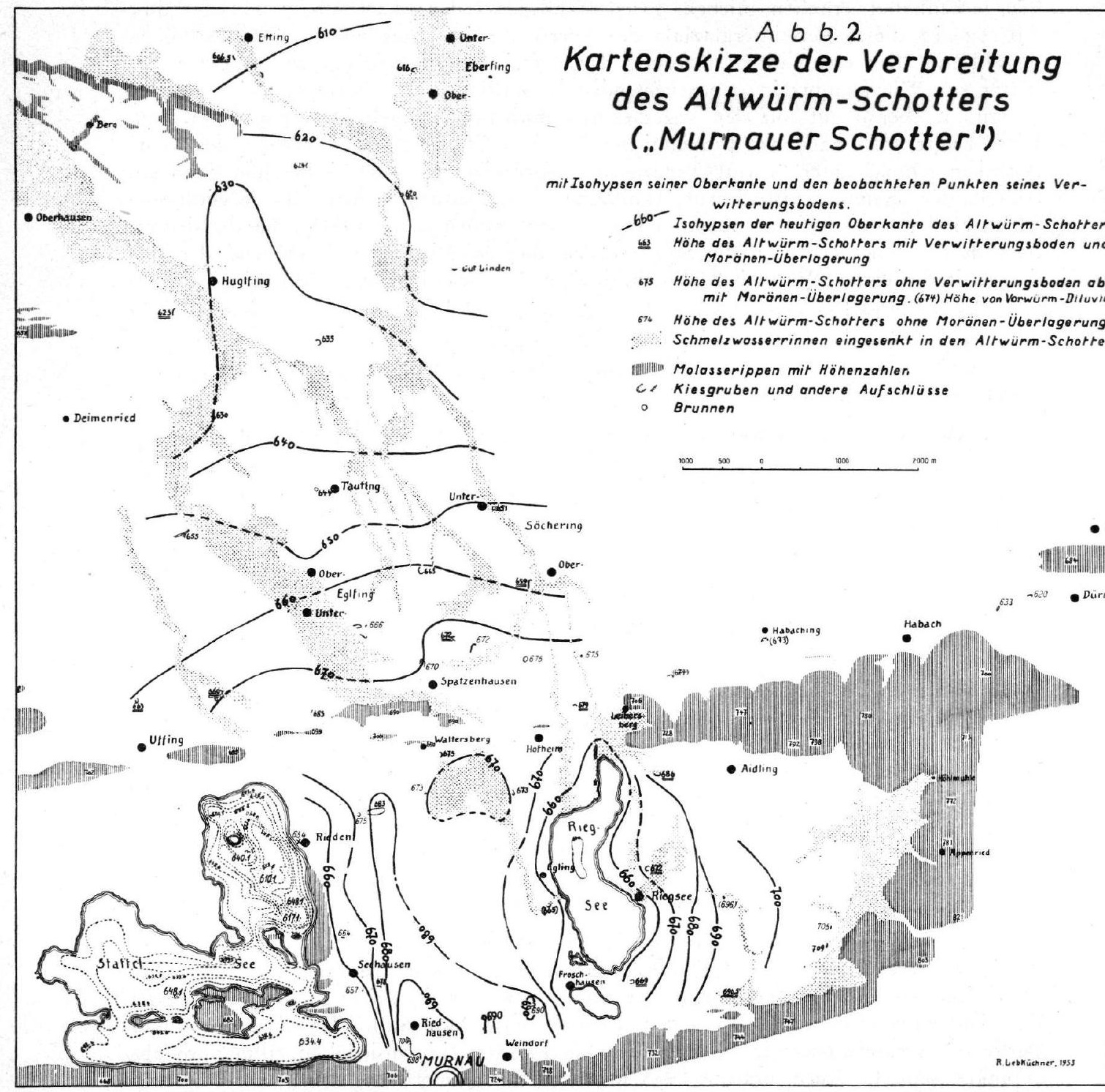

V e r b r e i t u n g. Mit der Verbreitung des Mu.Sch. hatten sich besonders D. Aigner (1913), A. Rothpletz (1917), und C. Troll (1937) beschäftigt. Auf Grund langdauernder Geländearbeit zeichnete R. LeBкüchner die Karte Abb. 2.

Von dem rippenartig heraustretenden Südflügel der Murnauer Molassemulde in $690-700 \mathrm{~m} \mathrm{MH}$. an erfüllt unser Schotter das Innere dieser Mulde über $10 \mathrm{~km}$ ostwestlicher Breite. Entsprechend den gleichfalls als Härtling wiederauftauchenden Konglomerat- und Sandsteinbänken (Nesselburgschichten des Chatts) wird hier der Mu.Sch. dünner, hat aber weiterhin, nordwärts bis $40 \mathrm{~m}$ mächtig werdend, den Bereich der Rottenbuch-Penzberger Molasse überschüttet (Abb. 3). Mit allmählich verminderter Mächtigkeit zieht er über Huglfing (Basis hier $610 \mathrm{~m}$ MH.) - Eberfing hinaus, wo er w. des Eberfinger Teilbeckens im Anger- und Weidenbachtal angeschnitten wurde. 
NO-wärts ist Mu.Sch. über Leibersberg hinaus im Bereich des Eberfinger Drumlinfeldes (E. EBErs 1925, 1926, 1937) nicht festgestellt, auch nicht jenseits davon. Denn die von A. Rothpletz (1917, S. 62) für den Mu.Sch. in Anspruch genommenen Kiesgruben bei Ellmanns enthalten ganz eisrandnahe, blockreiche, höchst unregelmäßig glazialgestörte Lockersande und Kiese. Sie gleichen völlig den übrigen jungeiszeitlichen, eisrandnächsten Übergängen zwischen Schottermoränen und fluvioglazialem Kies.

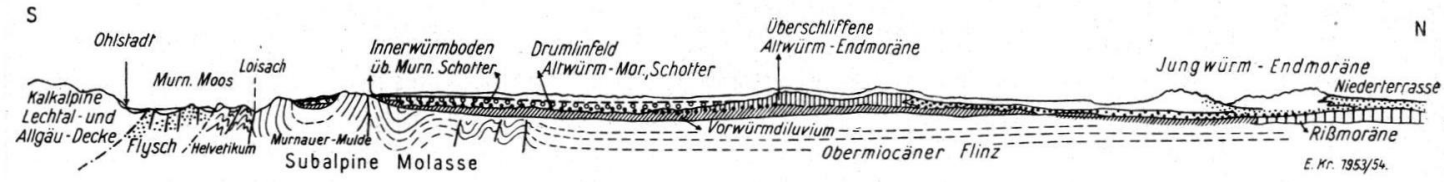

Abb. 3. Schematisches Profil (ohne Maßstab) zur Veransçhaulichung der Lage des Innerwürmbodens (dicke Linie) unter dem Jungdiluvium (ohne Signatur).

Allein proximal, am SO-Beginn des Drumlinfeldes, wo im S davon das harte Hochrelief der Murnauer Molassemulde ostwärts aushebt, da sind in den Kiesgruben ö. und onö. Habach die echten Murnauer Schotter 630-610 m hoch aufgeschlossen, $10 \mathrm{~m}$ eingeschnitten unter der ebenen Oberkante dieses Mu.Sch. Außerdem liegt im SO über dem Pelitletten bzw. über der Schieferkohle von Großweil nach A. RothPLETz (und meiner Beobachtung) auch wieder Mu.Sch. Ob er das jungwürmisch gepflügte Eberfinger Drumlinfeld, was wahrscheinlich ist, unterteuft, das ist noch nicht klar. Ostwärts erwähnt A. Rothpletz 1917 ähnliche Altwürmschotter.

A l tw ürmschotter. Bekannt ist dieser „Untere“ Schotter mit oft reichlich Kristallingeröll als Sockel unter den Jungwürmablagerungen im südbayerischen Alpenvorland weithin bis unter J. KNAUER's verschliffene W I-Endmoräne, ja bis unter die äußere Würmendmoräne. C. TROLL unterstrich dies z. B. 1924 und 1936. Er deutete, wie oben gesagt, diesen Schotter, der ein Rückgrat des Jungdiluviums darstellt, entsprechend allgemeiner Auffassung als Sediment der Vorrïckungsphase zur Würmvergletscherung.

Es entspricht dies auch den von J. KNAUER (1935, S. 10) angeführten Gründen für die Zugehörigkeit der Altwürmschotter nicht zum Riß-, sondern zum Würmsystem. Ersteres sei, wie auch allgemein bestätigt werden kann, in Moräne und Schotter meist lehmig etwas verunreinigt und hebe sich durch seinen erheblicheren Konglomerierungsgrad deutlich ab vom Würmsediment. Die intensive Rilßverwitterungsrinde ist in diesem ganz unbekannt. Freilich wurde die Würmgrundmoräne des bis zur KNAuER'schen "W I“-Randlage über den Altwürmvorrückungsschotter vorgeflossenen Eises oft nicht festgestellt, was seine Gründe haben muß - abgesehen von den sehr ungünstigen Aufschlußverhältnissen.

Wohl liegt auch über unserer als altwürmisch anerkannten Mu.Sch.-Vertretung eine Grundmoräne. Diese geht aber heran bis an die Außenmoränen und ist somit jungwürmisch. Oder sollte sich $\mathrm{n} \mathrm{a} \mathrm{ch} \mathrm{der} \mathrm{eisfreien} \mathrm{Innerwürmzeit} \mathrm{während} \mathrm{der} \mathrm{Grund-}$ moränen-Zeit in der Murnauer Gegend die letzte Vorstoßperiode der Würmzeit n o c h $\mathrm{mals}$ glieder $\mathrm{n}$ in ein erstes Stadium der Zungenbeckenbildung und Endmoränenlage in der überschliffenen Zone und in ein zweites Stadium des maximalen WürmVorstoßes? Nach dem von mir Gesehenen scheint dies eine denkbare Lösung zu sein. Will man noch "W I bis III" beibehalten, so müßte das "W I"-Eis den Alpenrand noch nicht erreicht, jedoch den Altwürmschotter vorgeschüttet haben. Das „W II“-Eis hätte seine stadiale Randlage an der überschliffenen Zone gehabt (Punktlinie in Abb. 4), das „W III“-Eis wäre bis an die äußersten Endmoränen vorgestoßen. 
Höhenlage der Mu.Sch.; Relief von Staffelsee und Riegsee. (Abb. 2 bringt neue Einzelheiten (hauptsächlich von R. LEBKüCHNER) über

1. die gegenwärtige Höhenlage des Mu.Sch.,

2. die Verbreitung des auf diesem derzeit aufgeschlossenen Innerwürm-Verwitterungs-bodens unter der jungen Grundmoräne,

3. die Schmelzwasserrinnen in der Terrassenoberfläche des Mu.Sch.,

4. Aufschlüsse, Brunnen.

Die Höhenkurven der Schotteroberfläche zeigen die beiden Hauptsenken an, welche heute den Riegsee bzw. den Staffelsee beherbergen. Deren Seespiegel liegen rund $50 \mathrm{~m}$ (auf 653 bzw. 648,6 m MH.) unter der hier ursprünglich offenbar allgemein gegen $700 \mathrm{~m}$ MH. hoch gewesenen Terrassen-Fläche des Mu.Sch. Der Boden des Riegsees reicht nur wenig unter $640 \mathrm{~m}$, jener. des $38,1 \mathrm{~m}$ tiefen Staffelsees aber auf 610,5 m MH. hinab. C. Troll sprach sich 1937 über die Bildung dieser Seebecken aus.

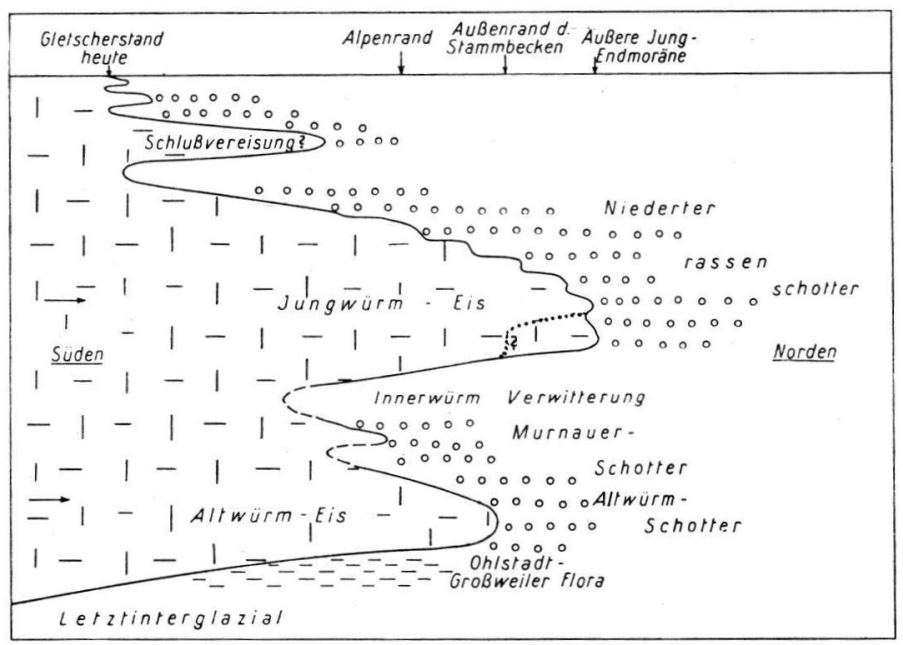

Abb. 4. Versuch einer schematischen. Darstellung der Eisrandlagen des Loisach-Ammerseegletschers und seiner fluvioglazialen Vorschüttung während des W'ürmsystems. (Profil).

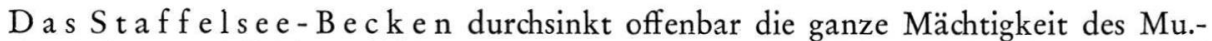
Sch. und dessen vielleicht erhaltene älterdiluviale Unterlage bis auf den.Molassesockel. Dieser steht am S- und SO-Ufer sowie an den Inseln an (W. ZEIL \& A. HAGN 1954).

Sehr bezeichnend wurde bei der neuen Auslotung des Staffelsees durch Fr. Zonel. (1951) die zwiefältige Reliefform dieses Seebeckens herausgearbeitet. Das Südrelief ist W-O-geordnet. Hier herrschen, meist steilgestellt, die harten Konglomerate und Sandsteinrippen im Südflügel der Murnauer Mulde. Eine Teilmuldung kommt dabei höchstens durch den flachen Seehauser Sattel ins Spiel. Der vorwiegend mergelige Molassekern der etwas N-überkippten Mulde ist in der i. a. sanfter geböschten Becken-Nordhälfte dagegen zunehmend glazial überlagert und überformt. Dabei wurde hier e in e NW-Richtung maßgebend. Sie kam offenbar zustande durch Kompromißbewegungen in der Grenzzone zweier Würm-Vorlandgletscher: des mächtigen Ammerseegletschers und des schwächeren Ammergaugletschers. Während ersterer im S aus dem Loisachquertal durch die Weite des Murnauer Mooses machtvoll geradeaus die Murnauer Mulde überfluten konnte und sich über die weite Ebene des Mu.Sch. besonders gegen NW ohne Hindernis auszubreiten vermochte, drängte er den wenig gut ernährten Ammergau-Gletscher in die westliche Nachbarschaft zurück (vgl. die Moränenwälle auf 
der Übersichtskarte von A. Rothpletz 1917). So ist die eigenartige Beckengestalt des Staffelsees wohl verständlich.

D i e Ri e g s e - S e nke. Warum aber konnte ö. vom Staffelsee noch eine zweite Teilsenke entstehen, in der heute der flachere Riegsee liegt?

Dem südgerichteten Sporn von Hechendorf können wir eine Trennung des Eisstromes in zwei Teile nicht zutrauen. Denn der durch Blattverschiebungen nur unbedeutend zerbrochene Molassemuldensüdflügel läuft ja hier gerade mit den weichen Basalmergeln der Unteren Meeresmolasse durch und hatte gegen seine O- und W-Fortsetzung keine bevorzugte Härte. Die Mergel dieses Spornes konnten also das Eis auf die Dauer nicht zweiteilen.

Aber was sich gegen den mehr W-O-streichenden Unterbau des Murnauer Moosbeckens ostwärts ändert, das ist die scharfe Zerstückelung des helvetidischen und des Flysch-Unterbaues durch NO-streichende und zwar auch noch junge Querverschiebungen. Solche stoßen hier in Verlängerung des Loisachquertales aus diesem heraus, haben dessen ungewöhnlich tiefe Ausräumung (350 bis $400 \mathrm{~m}$ mächtige, heutige Talfüllung!) tektonisch vorbereitet und schufen auch weiter gegen $\mathrm{NO}$ zu Kerbrinnen des Reliefs. Wie Führungsschienen wirkten diese offenbar auf die Richtung des Loisach-Eis-Stromes und lenkten dessen O-Teil im östlichen Murnauer Moosbecken gegen NO ab. Zunächst, basal, wurde der Eisstromstrich durch die harten Südrippen der Murnauer Mulde weiter gegen ONO abgedreht, hinaus in das Kochelseebecken. Als das Eis aber bis zur Höhe der Mulden-Südrippe angeschwollen war, schob sich die hangende Eismasse offensichtlich frontal mit ihrem nur etwas östlicher verlegten Stromstrich über die Murnauer Mulde geradeaus nach $\mathrm{N}$ vor. In der Trennzone des Eiskuchens konnte so der Hechendorfer Mergelsporn von der Wegräumung verschont bleiben. Jedoch schürfte der östlichere Stromstrich, etwas später und nur mit einem etwas abgelenktern Stromteil nordwärts weiter. Daher konnte er allein in dem weicheren Mergelkern der Murnauer Mulde - also etwas nördlicher als der Staffelsee - in den Murnauer Schotter die ungleich sanftere Senke des Riegsees ausgraben.

So blieb außer dem Hechendorfer Mergelsporn auch die südnördliche Teilschwelle im Mu.Sch. zwischen den beiden Seebecken bei Murnau übrig.

Nordteil und Ostfortsetzung des Murnauer Schotters. Leicht verständlich ist das flache Aufsteigen der genannten zwei Teilbecken gegen N. Hier wurde ja die glaziale Ausräumung des Mu.Sch. stark gehemmt durch den harten Muldennordflügel (Abb. 3). Darum mußte der schon primär dünnere Schotter hier auch selbst schon felsige Teilaufragungen umfließen. Mit geringeren Mächtigkeits- und Gefällsänderungen, welche erst nach zahlreichen Bohrungen zu erläutern wären, floß von da ab der wieder geschlossene Schotter dank seiner mäandrierenden Gewässer in allgemein nördlicher Richtung ab. Als Haupthärtling hinderte seine Ausbreitung gegen $\mathrm{O}$ der östlichste, höchste Endteil der hier umlaufenden Molassemulde. Wir finden den Mu.Sch. heute auch im Loisachtal ö. Schwaiganger nicht mehr über der nichtglazialen Serie, sondern erst wieder auf der Großweiler Schieferkohle. Von da im O herum um das Muldenende setzt sich der Mu.Sch. mit wohl $30 \mathrm{~m}$ Mächtigkeit bei Habach fort. Innerhalb der östlichen Murnauer Mulde reicht unser Schotter nur wenig über $700 \mathrm{~m}$ MH. empor. Im einzelnen gelang es der sorgfältigen Untersuchung durch R. LEBKücHNER an der Terrassenoberkante des Mu.Sch. noch kleinere und offenbar jungwürmischen Schmelzwässern zu dankende Teilrinnen mit Kies- oder Sandfüllung nachzuweisen. Hauptrinnen hat C. TROLL bereits 1937 erkannt.

Diluviale Unterlage. NO. Leimersberg bei (674) auf Abb. 2 zeigte sich, daß der Mu.Sch. keineswegs überall der Molasse aufgeschüttet wurde. Dazwischen erscheinen offensichtlich rißeiszeitliche Konglomerate mit wenig Kristallin, mit unfrischem 
Sediment und massiver Nagelfluh, in die eine Orgel mit 1,2 m dunkelbraunem Lehmkiesboden eingesenkt ist. Bei Stelle (673) der gleichen Abb. 2 (Habaching) liegt kräftig kreßfarbener Verwitterungsboden auf harter Nagelfluh unter Würmmoräne; bei (665) südlich Egling im W des Riegsees fand sich unter Würmgrundmoräne ziemlich hart verkittete Nagelfluh mit wenig Kristallin.

Die typische Terrassenebene des Mu.Sch. ist offenbar über- und angelagert diesen Untergrundsaufragungen aus älterem Diluvium, welche hier dank ihrer Härte sowie wegen des Schutzes vor der Eisexaration am Nordrand der Härtlinge der Murnauer Mulde erhalten bleiben konnten.

Die Bildung des Murna uer Schotters wird man sich wohl vorzustellen haben als eine fluvioglaziale Vorschüttung von einer Stillstandslage des Loisachgletschers aus, der am Gebirgsrand anhielt. Über die letztinterglaziale Serie mit ihren Pelitschlammlagen, über noch nahezu kristallinfreie kalkalpine Schotter und über die bei Ohlstadt mindestens zweimal vermoorten Senken des letztinterglazialen Murnauer Mooses hinweg schoben die altwürmischen Schmelzwässer durch das Loisachtal sowie dann auch nordwärts über die Murnauer Mulde den Mu.Sch. vor. Danach aber bekamen die Gewässer auch schon reichlichere Kristallingeschiebe zu fassen, die inzwischen würmglazial aus den Zentralalpen über den Fernpaß an die nahen Endmoränen vorgeschleppt worden waren. Dieses Einsetzen der Kristallingerölle kann als ein typisches Merkmal der beginnenden ersten Würmhocheiszeit gewertet werden: Der Mu.Sch. ist noch ein Altwürmschotter. Er überrollte Molasse und älteres Diluvium mit Elephas antiquus soweit dieses die Verwitterungs- und Erosionsperiode der Riß/Würminterglazialzeit überstanden hatte.

Als Altwürm-Stadial erweist sich die Murnauer Schotter-Vorschüttung durch die südwärts zunehmenden Anzeichen der Eisrandnähe, von der während eines Eisrandstillstandes am Alpenrande der Mu.Schotter ausging.

Aber dieser kann in seinem Oberteil nicht mehr als Vorstoßschotter gelten, den etwa der Jungwürmschotter alsbald überfuhr. Trägt er doch die ausgedehnte Verwitterungsrinde. Diese zeugt von einer erheblichen Klimaerwärmung, so daß nach dem Stillstand des Loisachgletschers am Alpenrand nun erst wieder mit einem bedeutenden $\mathrm{Zu}$ rückschmelzen desselben für längere Zeit in das Hochgebirge zurück gerechnet werden muß.

Noch weiter müssen die Gletscher schon vorher während der Letztinterglazialzeit gegen die Gebirgskämme zurückgegangen sein, um dann zur Zeit der Großweiler Schieferkohlen allmählich wieder anzuwachsen. Zwar hat sich in unserem engeren Arbeitsbereich noch kein sicherer Aufschluß mit Altwürmmoräne als Beweis für diesen ältesten Vorstoß des Loisach-Ammersee-Würmeises finden lassen. Aber diese Grundmoräne war wohl auch nicht mächtiger als die des Jungwürm-Eisvorstoßes bis zu den äußersten Fndmoränen, so daß die Schmelzwässer des Rückzuges dann weithin die Reste wegräumen konnten. Abb. 4 versucht schematisch mit einer Kurve dieses Hin und Her des jungdiluvialen Eisrandes dauzstellen.

Die Ausräumung des Murnauer Schotters. Wie schon A. Penck (1922, S. 224) und, in abgeänderter und sehr interessanter Weise, C. TroLL (1937) ausgeführt haben, dürfte unser Mu.Sch. auch jenseits über die Ohlstadt-Großweiler Serie hinaus ins Kocheler Stammbecken gelangt sein. Aber über seinen Resten am Bekkenwestrand ist keine Verwitterungsrinde erhalten, und an der Beckenoberfläche ist der Schotter nicht bekannt. Sein typischer höherer Gehalt an Kristallingeröll beginnt erst bei Schnait im Loisachtal gegen Schwaiganger zu einzusetzen, östlich fehlt solcher Schotter, außer dann wieder bei Großweil. Es kann hieraus geschlossen werden, daß wahrscheinlich schon beginnend während der Verwitterung des zwischen den schützen- 
den Reliefrand-Rippen der Murnauer Mulde und n. davon erhalten gebliebenen Mu.Sch. - dieser von der Kochelseesenke her Loisach-aufwärts fluviatil stark ausgeräumt wurde. Das verstärkte sich, als das Eis der späteren Jungwürm- Vergletscherung das Diluvium in dem zunächst engeren Urloisach-Kerbtal s. der Murnauer Mulde und im $\mathrm{N}$ des Flyschgebirges ausgrub mitsamt dem hangenden, noch wenig verfestigten Mu.Sch. Erst dort, wo sich dieser geschützt befand in der tieferen Lage der Talausweitung gegen das Kochelseebecken bei Großweil über der Braunkohle, dort konnte er sich bis heute erhalten. Spätglazial wurde er im W des Kochelseebeckens z. T. ersetzt durch C. TroLL's Randterrassen.

D e r B e trag solcher Ausräumung, welcher, allein nach den heutigen Höhenunterschieden, auf $30-50 \mathrm{~m}$ zu schätzen wäre, ist nicht näher feststellbar. Denn wir kennen nicht den Umfang der jungen, vertikalen Verschiebungen an der steilen Längsstörung zwischen Molasse und Gebirge. Diese Ausräumung macht verständlich, weshalb auch kein Rest eines Verwitterungsbodens zwischen dem noch wenig Kristallin führenden Basalschotter der Großweiler Serie und der hangenden Jungmoräne aufzufinden war.

Infolge der scharfen Reliefverengung im Loisachtal unterhalb Ohlstadt und wegen seines Gefälles gegen $\mathrm{O}$ war die Ausräumung erheblich. Ihr stand gegenüber eine sehr geringe Basal-Exaration, eher eine Basalschonung des Mu.Sch. durch das Jungmoräneneis in der hochliegenden, also geschützteren Murnauer Mulde und der sanft nördlich abgedachten Murnauer Schotterebene nordwärts davon. Hier floß das Eis offenbar ohne Reliefhemmung gegen NW, N, NO breiartig auseinander. Darum konnte hier a uch ein Innerwürmboden erhalten bleiben.

\section{Die Innerwürmverwitterung des Murnauer Schotters}

Vorkommen im Gelände. Oben wurde begründet, warum in den Kiesgruben immer nur unter geringmächtiger Jungeis-Grundmoräne unser Boden zu beobachten ist. Man sieht ihn auch da oft schwer, weil der Regen den an den Gruben-Steilböschungen heraustretenden Verwitterungslehm auswäscht. Daher unterscheiden sich, feucht und ausgetrocknet, die Farben der ausstreichenden Horizonte nur wenig. Erst Schürfarbeit mit tüchtiger Hacke öffnet, dann freilich sofort, das klare Profil mit den unterscheidenden Farben (Abb. 5). Begünstigt waren 1953 unsere Untersuchungen durch die gesteigerte Schottergewinnung "dank" des sehr ausbesserungsbedürftigen Zustandes unserer zerfahrenen Landstraßen.

Man hat wohl meist nicht die Gewohnheit, an einer Grubenwand emporzusteigen, die steil, bei Konglomerierung wandartig ist. Und die hangende Grundmoräne zu oberst löst sich - ganz wie etwa der nordische Geschiebemergel - an senkrechten Kluftlächen $a b$, was ein Herankommen an den Verwitterungsboden auch von oben sehr erschwert. Immerhin brachte mir zu günstiger Zeit ein Blick auf den obersten Teil des nördlicheren der beiden großen Kiesgruben w. Huglfing deshalb die Entdeckung der Verwitterungsschicht, weil hier die $\mathrm{Tr}$ ichter, mit denen der Verwitterungshorizont in den Murnauer Schotter hinabgreift, auch von unten erkennbar waren. Trichter dieser Art gibt es ja an der Sohle übergreifender Grundmoränen nicht.

Das Jungwürmeis überfloß hier, wie oben gesagt, eine Terrassenoberfläche, so daß die Fließbelastung durch das mächtige Eis recht ausgeglichen war. Der unterlagernde Schotter schluckte zwar subglaziale Schmelzwässer, war aber so fest gelagert, daß er bei fehlenden Unebenheiten des Reliefs nicht das bekannte, wellig-grubige Relief anderer Eis- bzw. Moränenunterflächen annahm. Im Gegenteil kann man sehr ebene, ja oft messerscharf glatte Sohlflächen der Grundmoräne über unseren Bodenresten beobachten. Solche Grenzebenen sprechen eher für ein gewisses Horizontalgleiten des Hangenden, nicht aber für ein Eingraben. Unter solchen Umständen fehlt die Exaration fast ganz. 
Einzelbeobachtungen. Die Kiesgruben mit Verwitterungsboden zwischen Mu.Sch. und Grundmoräne sind in Abb. 2 vermerkt und in vorstehender Tabelle I aufgeführt. Einige typische Profile seien beschrieben:

In der genannten Kiesgrube SW Huglfing hat man von oben nach unten:

Bis 3,00 m Grundmoräne mit gekritzten Geschieben, wenig Kies

Bis $0,40 \mathrm{~m}$ braune Trichterzapfenzone des Bodens: lehmig verbundener Kies (C-Horizont) Probe I der Tabelle III

$25 \mathrm{~m}$ hoher Grubensteilhang des Mu.Sch. darin rd. $10 \mathrm{~m}$ über der Talsohle Eisenrostlage (dünn), offenbar von altem Grundwasserhorizont.

Die Grundmoräne steigt gegen W über $15 \mathrm{~m}$ an, wo bei Neuanlage eines WasserHochbehälters über $6 \mathrm{~m}$ Grundmoräne aufgeschlossen worden war. Unter Grundmoräne und mit Zapfen auf dem Mu.Sch. liegt derselbe braune Verwitterungsboden, bis $35 \mathrm{~cm}$ mächtig, in der Kiesgrube bei Etting $606,5 \mathrm{~m}$; bei Spatzenhausen-N. dunkelbrauner, kiesiger Lehm, $672 \mathrm{~m}$ hoch, unter $1 \mathrm{~m}$ Grundmoräne mit völlig glatter Unterfläche (Abb. 5). Daneben ist ein Block des Geschiebemergels abwärts eingedrückt in $20 \mathrm{~cm}$

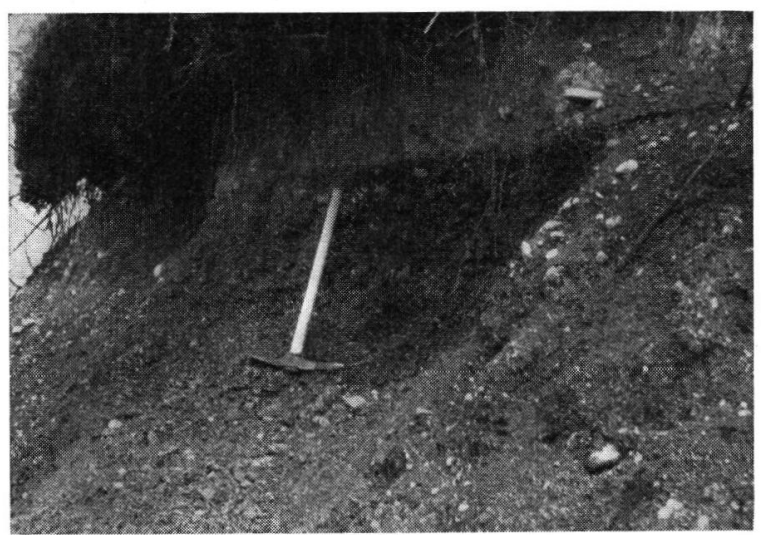

Abb. 5. Innerwürmboden (kiesiger, brauner Lehm, schwache Reaktion auf verd. $\mathrm{HCl}$ ) aufgehackt (Hackenstiel $52 \mathrm{~cm}$ ) unter kalkreicher Grundmoräne $(1 \mathrm{~m}$ mit glatter Unterfläche). Verwitterungstrichter bis $25 \mathrm{~cm}$ tief, Kiesgrube in Murnauer Schotter bei P. 672 nördl. Spatzenhausen (Abb. 2).

braunen Lehm. $1 \mathrm{~km}$ südlich Obersöchering hat man das Profil der Abb. 6; nördlich von Kirche Uffing, von wo aus einer in der Grundmoräne mitgeführten Linse des Innerwürmbodens Probe II untersucht wurde, Abb. 7. NO. Kirche Hofheim (Probe III aus einem Zapfen) fand sich Abb. 8. Am Nordausgang von Dorf Riegsee (Bodenprobe IV) zeichnete ich Abb. 9. Östlich von Froschhausen südlich P. 702 wurde Probe V genommen (Abb. 10). Probe VI stammt von einem Weganschnitt SSO Kirche Hechendorf (Abb. 11), dürfte aber ein älterer Boden sein. Abb. 14 zeigt die Lage des Bodens im Gelände.

Versuch eines Vergleichs mit anderen Jungböden. Um etwas Greifbares hinsichtlich Art und Dauer der innerwürmischen Verwitterung zu gewinnen, zog ich einige jüngere, seit der letzten Eiszeit erst zur Verwitterung gelangte Böden auf Schottern zum Vergleich heran (vgl. Tabelle II, III). Von den etwa 7 Terrassenstufen der Inntalniederterrasse oberhalb Neuötting-Mühldorf-Ampfing konnten am wenigsten die obersten, ältesten Terrassenböden mit ihrem wohl ausgebildeten B-Horizont, der auch hier oft noch als kreßfarbener bis roter Blutlehm des postglazialen Kli- 
Tabelle I

\begin{tabular}{|c|c|c|c|c|c|c|c|}
\hline Nr. & Kiesgrube & $\begin{array}{c}\text { Mächtigkeit } \\
\text { des Bodens } \\
\mathbf{m}\end{array}$ & $\begin{array}{l}\text { Zapfen- } \\
\text { Länge } \\
\text { m }\end{array}$ & $\begin{array}{l}\text { Mächtigkeit } \\
\text { der } \\
\text { hangenden } \\
\text { Grundmoräne }\end{array}$ & $\begin{array}{c}\text { Mächtigkeit des } \\
\text { Murn.-Schotfers } \\
\text { aufgeschlossen } \\
\text { m }\end{array}$ & $\begin{array}{l}\text { Hinweis auf } \\
\text { Abbildungen }\end{array}$ & $\begin{array}{c}\text { Nr. } \\
\text { der chem. } \\
\text { Analyse }\end{array}$ \\
\hline 1 & (S) W Etting & bis 0,35 & 0,3 & $>1,5$ & 8 & Abb. 2, P. 606,5 & \\
\hline 2 & $\begin{array}{l}\text { An Straße n. } \\
\text { Spatzenhausen }\end{array}$ & bis 0,5 & bis 0,25 & 1,5 & 6 & $\begin{array}{c}\text { Abb. 2, P. } 672 \\
\text { Abb. } 5\end{array}$ & \\
\hline 3 & $\begin{array}{l}\text { Obersöchering } \\
\text { SW-Ausgang }\end{array}$ & $\begin{array}{c}0,25 \\
+ \text { etw. Moräne }\end{array}$ & 0,25 & 1,0 & $>7$ & $\begin{array}{c}\text { Abb. 2, P. } 659 \\
\text { Abb. } 6\end{array}$ & \\
\hline 4 & $\begin{array}{l}\text { Nahe ö. N-Ende des } \\
\text { Rieg-Sees }\end{array}$ & $0,2-0,4$ & 0,1 & $>1,0$ & $>4$ & Abb. 2, P. 686 & \\
\hline 5 & S. Hofheim n. P. & 0,1 & 0,1 & $>1,0$ & $>3$ & Abb. 2, P. 673 & \\
\hline 6 & $1 \mathrm{~km} \ddot{0}$. Froschhausen & 0,2 & 0,2 & 2,0 & 8 & Abb. 2, P. 669 & \\
\hline 7 & o. Station Uffing & - & 0,15 & 1,6 & $\begin{array}{l}\text { 4, über Nagel- } \\
\text { Fluh }\end{array}$ & Abb. 2, P. 669,7 & $\begin{array}{l}\text { Gerölle } \\
\text { Mn-braun } \\
\text { umrindet }\end{array}$ \\
\hline 8 & W. Huglfing & bis 0,4 & $0,2-0,3$ & bis 3 & $>25$ & Abb. 2, P. 625 & 1 \\
\hline 9 & $\begin{array}{l}550 \mathrm{~m} n \text {. Kirche } \\
\text { Uffing }\end{array}$ & bis 1,25 & 0,3 & 2,3 & $>3$ & $\begin{array}{l}\text { Abb. 2, P. } 663 \\
\text { Abb. } 7\end{array}$ & II \\
\hline 10 & $\begin{array}{c}650 \mathrm{~m} \text { nö. Kirche } \\
\text { Hofheim }\end{array}$ & - & 0,4 & 0,75 & $>4$ & $\begin{array}{c}\text { Abb. 2, P. } 679 \\
\text { Abb. } 8\end{array}$ & III \\
\hline 11 & $\begin{array}{c}\text { Dorf Riegsee } \\
\text { N-Ausgang }\end{array}$ & $0,1-1,0$ & 0,6 & $1,5-2,5$ & 6 & $\begin{array}{l}\text { Abb. 2, P. } 672 \\
\text { Abb. } 9\end{array}$ & IV \\
\hline 12 & $\begin{array}{l}\text { ö. Froschhausen } \\
\text { s. Punkt } 702\end{array}$ & $0,3-0,5$ & 0,15 & 1,2 & $>4$ & $\begin{array}{l}\text { Abb. 2, P. } 696,5 \\
\text { Abb. } 10\end{array}$ & v \\
\hline 13 & $\begin{array}{l}50 \mathrm{~m} \text { s. Kirche } \\
\text { Hechendorf }\end{array}$ & $0,3-0,5$ & - & 0,55 & $>0,5$, ? Mu. Sch. & $\begin{array}{c}650 \mathrm{~m} \text { MH } \\
\text { Abb. } 11\end{array}$ & VI \\
\hline 14 & $\begin{array}{l}250 \mathrm{~m} \text { sW. Kirche Ebing } \\
\text { linkes Innufer }\end{array}$ & $\begin{array}{l}\text { A: } 0,3-0,4 \\
\text { B: } 0,2-0,4\end{array}$ & $0,1 \cdot 0,3$ & - & $\begin{array}{c}\text { Ebinger } \\
\text { Niederterrasse }\end{array}$ & - & VII \\
\hline 15 & $\begin{array}{c}250 \mathrm{~m} \text { WSW. Kirche } \\
\text { Pürten }\end{array}$ & $\begin{array}{l}\text { A: } 0,35 \\
\text { B: } 0,35\end{array}$ & 0,2 & - & $\begin{array}{c}\text { Pürtener } \\
\text { Niederterrasse }\end{array}$ & - & VIII \\
\hline
\end{tabular}

Tabelle II

\begin{tabular}{|c|c|c|c|c|c|c|c|c|c|c|}
\hline Nr. & $\begin{array}{c}\text { Bodenanalyse } \\
\text { nach Bi. Ampfing, Erläut. }\end{array}$ & $\mathrm{H}_{2} \mathrm{O}$ & $\begin{array}{l}\text { Glüh- } \\
\text { verlust }\end{array}$ & $\mathrm{CO}_{2}$ & $\mathrm{P}_{2} \mathrm{O}_{3}$ & $\mathrm{Al}_{2} \mathbf{O}_{3}$ & $\mathrm{Fe}_{2} \mathrm{O}_{3}$ & \begin{tabular}{|l} 
Fe2 03 \\
in \% d. \\
Sesquiox
\end{tabular} & $\mathrm{CaO} O$ & $\mathrm{MgO}$ \\
\hline 16 & $\begin{array}{l}\text { Pürtener Stufe } J_{12} \\
\text { Feinerde }\end{array}$ & 1,79 & 6,56 & - & 7,03 & 0,41 & 6,62 & 94,6 & 0,34 & 0,14 \\
\hline 17 & $\begin{array}{l}\text { Niederndorfer Stufe } \\
\text { G4 von BI. Gars }\end{array}$ & 2,30 & 10,03 & - & 4,37 & 0,31 & 4,06 & 92,9 & 0,54 & 0,32 \\
\hline 18 & $\begin{array}{l}\text { Niederndorfer Stufe } \\
\text { J5 von Bl. Gars }\end{array}$ & 1,31 & 5,90 & - & 8,33 & 0,89 & 7,44 & 89,3 & 0,36 & 0,07 \\
\hline
\end{tabular}


Tabelle III

\begin{tabular}{|c|c|c|c|c|c|}
\hline & Rohboden & $\begin{array}{l}\text { Steine } \\
\text { über } 2 \mathrm{~mm}\end{array}$ & $\begin{array}{l}\text { Feinerde } \\
\text { unter } 2 \mathrm{~mm}\end{array}$ & $\begin{array}{c}\mathrm{H}_{2} \mathrm{O} \\
\text { bei } 105^{\circ} \mathrm{C}\end{array}$ & $\begin{array}{l}\text { Glühverlust } \\
\left(\mathrm{H}_{2} \mathrm{O} \text { über }\right. \\
105^{\circ} \mathrm{C} \text { org. } \\
\text { Substanz } \\
\left.+\mathrm{CO}_{2}\right)\end{array}$ \\
\hline & & \multicolumn{2}{|c|}{$\begin{array}{c}\text { in } \mathrm{g} \text { und in } \% \text { des } \\
\text { Rohbodens }\end{array}$} & & \\
\hline $\begin{array}{l}\text { Probe I }=\text { Nr. } 8 \\
\text { N. Kiesgrube SW } \\
\text { Huglfing: } \\
\text { Innerwürmboden } \\
\text { Blatt Weilheim. }\end{array}$ & $1070,6 \mathrm{~g}$ & $\begin{array}{l}877 \mathrm{~g} \\
(81,92 \%)\end{array}$ & $\begin{array}{l}193,60 \mathrm{~g} \\
(18,08 \%)\end{array}$ & 1,70 & 18,23 \\
\hline $\begin{array}{l}\text { Probe II }=\text { Nr. } 9 \\
550 \mathrm{~m} \text { N. Kirche Uffing, } \\
\text { Kiesgrube. Bl. Uffing: } \\
\text { Fetzen von Innerwürmboden } \\
\text { in Moräne. }\end{array}$ & $336,99 \mathrm{~g}$ & $\begin{array}{l}263,29 \mathrm{~g} \\
(78,13 \%)\end{array}$ & $\begin{array}{l}73,70 \mathrm{~g} \\
(21,87 \%)\end{array}$ & 1,00 & 32,99 \\
\hline $\begin{array}{l}\text { Probe III }=\text { Nr. } 10 \\
650 \mathrm{~m} \text { NO Kirche Hofheim, } \\
\text { Kiesgrube. B1. Murnau: } \\
\text { Zapfen des Innerwürmbo- } \\
\text { dens. }\end{array}$ & $1033,4 \mathrm{~g}$ & $\begin{array}{l}735,1 \mathrm{~g} \\
(71,14 \%)\end{array}$ & $\begin{array}{l}298,3 \mathrm{~g} \\
(28,86 \%)\end{array}$ & 1,79 & 30,66 \\
\hline $\begin{array}{l}\text { Probe IV = Nr. } 11 \\
\text { Nordausgang Dorf Riegsee. } \\
\text { Kiesgrube.Innerwürmboden. } \\
\text { Bl. Murnau. }\end{array}$ & $1383,5 \mathrm{~g}$ & $\begin{array}{l}986 \mathrm{~g} \\
(72,93 \%)\end{array}$ & $\begin{array}{l}397,5 \mathrm{~g} \\
(27,07 \%)\end{array}$ & 1,09 & 25,01 \\
\hline $\begin{array}{l}\text { Probe V }=\text { Nr. } 12 \\
\text { Ó. Froschhausen, S. Punkt } \\
\text { 702. B1. Murnau: } \\
\text { Innerwürmboden. }\end{array}$ & $944,2 \mathrm{~g}$ & $\begin{array}{l}519,9 \mathrm{~g} \\
(55,06 \%)\end{array}$ & $\begin{array}{l}424,3 \mathrm{~g} \\
(44,94 \%)\end{array}$ & 1,28 & 13,00 \\
\hline $\begin{array}{l}\text { Probe VI }=\text { Nr. } 13 \\
\text { OSO. Kirche Hechendorf, } \\
\text { wohl interglazialer Boden. } \\
\text { B1. Eschenlohe. }\end{array}$ & $925,4 \mathrm{~g}$ & $\begin{array}{l}255,6 \mathrm{~g} \\
(27,62 \%)\end{array}$ & $\begin{array}{l}669,8 \mathrm{~g} \\
(72,38 \%)\end{array}$ & 1,29 & 39,62 \\
\hline $\begin{array}{l}\text { Probe VII }=\text { Nr. } 14 \\
\text { A-Horizont unter Wiese } \\
\text { postglazialer Boden auf } \\
\text { Ebinger Stufe. N. Terr.- } \\
\text { Schotter. Kiesgrube } 250 \mathrm{~m} \\
\text { WSW Kirche Ebing a. Inn. }\end{array}$ & $924 \mathrm{~g}$ & $\begin{array}{l}379 \mathrm{~g} \\
(41,02 \%)\end{array}$ & $\begin{array}{l}545 \mathrm{~g} \\
(58,98 \%)\end{array}$ & 1,13 & 4,66 \\
\hline $\begin{array}{l}\text { Probe VIII = Nr. } 15 \\
\text { A-Horizont unter Wiese, } \\
30 \mathrm{~cm} \text { tief, postglazialer } \\
\text { Boden auf NT der Pür- } \\
\text { tener Stufe. Kiesgrube } \\
250 \mathrm{~m} \text { WSW Kirche Pürten } \\
\text { am Inn. }\end{array}$ & $905,35 \mathrm{~g}$ & $\begin{array}{l}352,95 \mathrm{~g} \\
(38,99 \%)\end{array}$ & $\begin{array}{l}552,40 \mathrm{~g} \\
(61,01 \%)\end{array}$ & 1,22 & 3,17 \\
\hline
\end{tabular}

*) Sämtliche Proben enthalten mehr oder weniger org. Substanz (Humus).

*) Die Kohlensäure ist in sämtlichen Proben dolomitisch gebunden. 
Untersuchungsergebnisse

\begin{tabular}{|c|c|c|c|c|c|c|c|}
\hline $\begin{array}{c}\mathrm{CO}_{2} \\
\text { (nach } \\
\text { Scheibler) }\end{array}$ & $\begin{array}{l}\text { entspricht } \\
\left.\mathrm{CaCO}_{3} *\right)\end{array}$ & $\mathrm{R}_{2} \mathrm{O}_{3}$ & $\mathrm{Al}_{2} \mathrm{O}_{3}$ & $\mathrm{Fe}_{2} \mathrm{O}_{3}$ & \multirow[t]{2}{*}{$\begin{array}{c}\mathrm{Fe}_{2} \mathrm{O}_{3} \\
\text { in \% der } \\
\text { Sesquioxyde }\end{array}$} & $\mathrm{CaO}$ & $\mathrm{MgO}$ \\
\hline \multicolumn{5}{|c|}{ in $\%$ der luftrockenen Feinerde } & & \multicolumn{2}{|c|}{$\begin{array}{c}\text { in } \% \text { der lufttrockenen } \\
\text { Feinerde }\end{array}$} \\
\hline 14,59 & 33,18 & 6,15 & 3,45 & 2,70 & 43,90 & 11,47 & 6,76 \\
\hline 28,46 & 64,73 & 5,50 & 3,84 & 1,66 & 30,18 & 24,60 & 9,73 \\
\hline 25,40 & 57,76 & 5,62 & 3,07 & 2,55 & 45,37 & 18,68 & 11,49 \\
\hline 23,31 & 53,01 & 4,84 & 2,73 & 2,11 & 43,60 & 15,84 & 10,50 \\
\hline 11,39 & 25,90 & 6,00 & 2,87 & 3,13 & 52,17 & 7,53 & 4,54 \\
\hline 36,83 & 83,77 & 5,62 & 2,72 & 2,90 & 51,60 & 24,03 & 16,27 \\
\hline 1,25 & 2,83 & 5,30 & 2,36 & 2,94 & 55,47 & 1,60 & 1,42 \\
\hline 0,09 & 0,20 & 6,49 & 2,51 & 3,98 & 61,33 & 0,57 & 0,93 \\
\hline
\end{tabular}




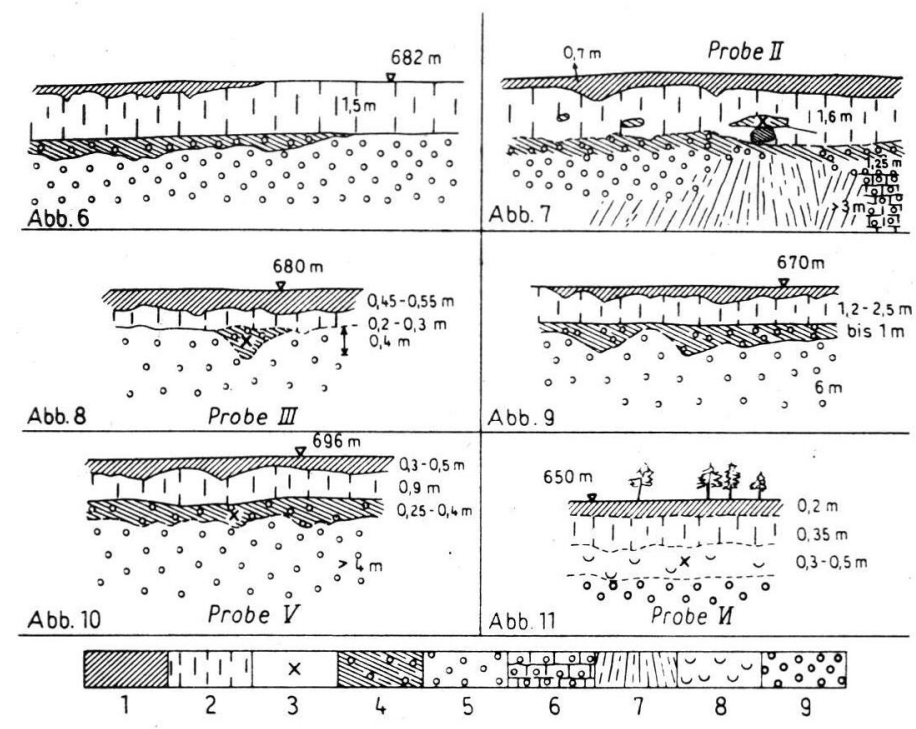

Abb. 6-11. Profilskizzen fossiler Böden bei Murnau (ohne Maßstab). 1 Nachwürm-Boden. 2 Jungwürm-Grundmoräne. 3 Entnahmestelle eine analysierten Bodenprobe. 4 Innerwürm-Boden. 5 Murnauer Schotter. 6 Derselbe örtlich zu Nagelfluh verkittet. 7 Hangschutt. 8 Düster-rötlichbrauner Lehm mit weißlichen, völlig zersetzten Geröllen. 9 Schotter ohne Kristallingeröll. Abb. 6-11 zeigen Kiesgruben des Murnauer Schotters und zwar bei nachgenannten Punkten (P.) auf Karte Abb. 2: Abb. 6 bei P. 659 SW. Obersöchering. Abb. 7 bei P. 663 N. Uffing; im Gegensatz zur Grundmoräne brausen die von ihr eingeschlossenen Bodenfetzen mit verd. $\mathrm{HCl}$ nicht. Abb. 8 bei P. 679, NO. Hofheim; Karbonatgerölle des auf verd. HCl nichtreagierenden Innerwürmbodens stark angeätzt. Abb. 9 bei P. 672 NO. Dorf Riegsee; vgl. dazu Abb. 12. Abb. 10 bei P. 696,5 O. Froschhausen; vgl. dazu Abb. 13. Abb. 11 an Wegkreuzung $50 \mathrm{~m} \mathrm{S.}$ Kirche Hechendorf.

maoptimums (E. Kraus $1921^{1}$ ) erscheint, für einen Vergleich mit unserem, eines BHorizonts entbehrenden Innerwürmboden in Frage kommen. Gering ist dieser Horizont schon auf der Ebinger Terrassenstufe (Bodenprobe VII). Bei Pürten auf der gleichnamigen (10 $\mathrm{m}$ tiefer als die Ebinger) noch jüngeren Stufe fehlt er noch ganz. In der Pürtener Kiesgrube an der Straße nach Kraiburg, wo etwa 65\% Kristallingeröll neben Kalk, Dolomit, Sandstein den Bestand bilden, sieht man nur 0,35 m hellbraunen, sandigen Lehm des A-Horizonts (Probe VIII) über $0,35 \mathrm{~m}$ braunem, lehmig-sandigem Kies, der eigentlich nur eine dunkeleisenschüssig-lehmige Umrindung der Gerölle des C-Horizonts darstellt. In Tabelle II wurden zum Vergleich auch einige Analysenergebnisse aus den Erläuterungen zu Blatt Ampfing aufgeführt.

12-15 m tiefer als die Pürtener begleitet die Niederndorfer Stufe den Inn. Weil sie aber bereits in den Flinz einschnitt, ist sie sehr tonmergelig-feinsandig, vielfach moorig, daher zum Vergleich mit unseren Schotterböden ungeeignet, obwohl sie Böden kürzester Verwitterungsdauer trägt, die zum Vergleich lehrreich hätten sein können.

Natürlich stehen einwandfreien Vergleichen solcher nachglazialer Schotterböden mit dem Innerwürmboden viele Schwierigkeiten entgegen. Das Klima der ersteren war wärmer, als es für letzteren anzunehmen ist. Der Innerwürmboden hat oft nur Zapfen mit infiltrierten Bodenresten; auch wurde er nach seiner Bildung erst noch vom Inland-

1) Kilometerlange Grabenaufschlüsse SO München, in denen der Blutlehm noch vo $r$ seiner -Degradierung in späterem Klima, durch eine Schlickdecke geschützt, intakt blieb, erwiesen hier die bodengeschichtlichen Folgerungen von 1921. 


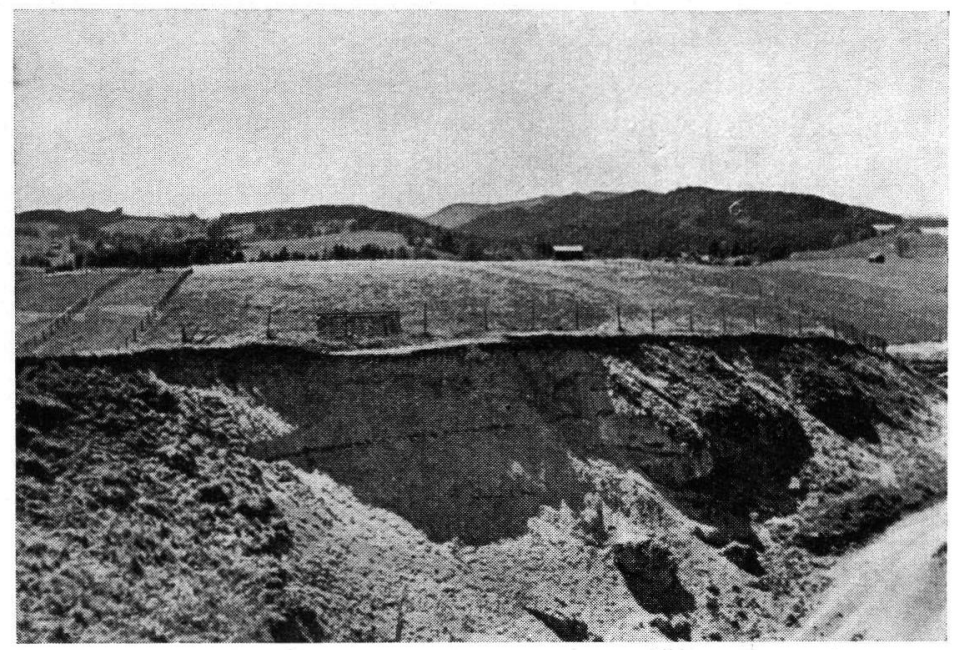

Abb. 12. In der Grube bei P. 672 (Abb. 9): links der Bildmitte Innerwürmboden, hier nur $3 / 4 \mathrm{~m}$ unter Grubenoberkante, welche ebene Terrassenfläche bildet. Rechts randliche Nagelfluhverkittung.

eis überfahren bei starker Pressung, Frostwirkung und langdauernder Durchsickerung durch salzarmes, humusfreies Schmelzwasser.

Aus solchen Gründen dürften sich einige sehr abweichende Analysenergebnisse (vgl. Tabelle III) verstehen lassen. So etwa das starke Überwiegen in den Sesquioxyden (aufgeschlossen nach 1 Stunde Behandlung mit conc. $\mathrm{HCl} 1: 1$ ) von $\mathrm{Fe}_{2} \mathrm{O}_{3}$ in den alluvialen Innschotterböden gegenüber dem Innerwürmboden. So stehen die aus dem hohen Glühverlust $(13-32 \%$ ) zu schließenden bedeutenden Mengen von Dolomit des (kaum mit $\mathrm{HCl}$ aufbrausenden) Innerwürmbodens gegenüber dem Glühverlust von nur 3-10\% am Inn - beides bei entsprechenden Mengen an $\mathrm{CaO}$ und $\mathrm{MgO}$. Die viel höheren Zahlen für $\mathrm{CaO}$ und $\mathrm{MgO}$ der Innerwürmböden und deren geringe Reaktion auf verd. Salzsäure im Gelände weisen hin auf die geringere chemische Verwitterung dieser Böden, wobei der Kalk aber früher entfernt wird als der Dolomit, der ja in $\mathrm{CO}_{2}$-haltigem, salzarmem Wasser erheblich schwerer löslich ist. Die Menge des Dolomitanteils auch unter $2 \mathrm{~mm}$ Korngröße versteht sich aus dem feingrusig zerfallenden

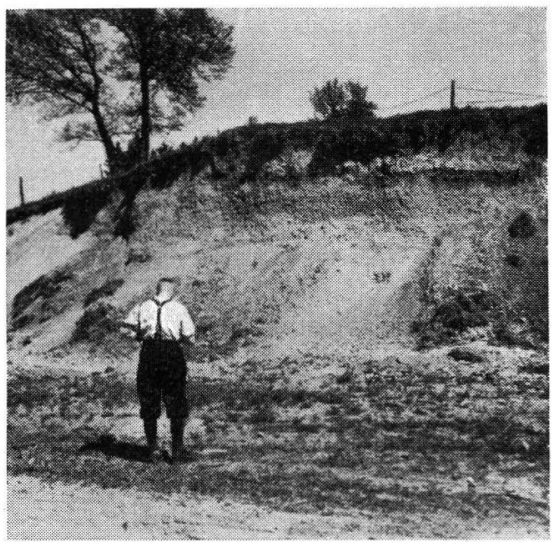

Abb. 13. In der Grube bei P. 696,5 (Abb. 10) tritt der dunklere Innerwürmboden auf dem Mu.Sch. unter der Grundmoräne deutlich heraus. 
Hauptdolomit des Einzugsgebietes, das für die betreffenden Inntalterrassen außerdem fünfmal ferner lag als bei Murnau.

Erfahrungsmäßig schwanken die Analysenwerte schon der Bodenproben aus der gleichen Kiesgrube recht bedeutend, so daß schon deshalb nur recht grobe und vorsichtige Schlüsse möglich sind. Man vergleiche z. B. nur die Analysen aus Böden auf der Pürtener Stufe No. VIII und No. 16. Viele, eingehende, vergleichende Untersuchungen werden besonders auch an fossilen Bodenresten oder "Restböden " nötig sein, bevor die jetzt noch erkennbaren, typischen Eigenschaften abweichender Klimata und verschiedener Verwitterungsdauer geklärt sein können. Daher sind unsere Versuche mehr Anregung und Material zu einer weiteren paläoklimatischen Bodenforschung.

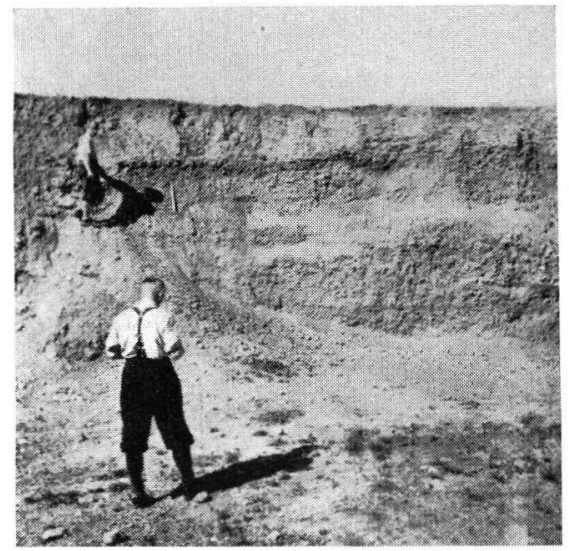

Abb. 14. Kiesgrube des Mu.Sch. bei P. 686 (Abb. 2) O. vom Nordende des Riegsees. Links in der Grube als dunkler Strich neben dem Mann der Innerwürmboden.

(Phot. S. Buchardt).

Nach ihren analytisch und geländemäßig faßbaren Folgen schreitet erfahrungsgemäß die Verwitterung recht langsam voran, bis erst die hinreichende Zerkleinerung der Gesteinskomponenten erreicht ist und die Vegetation hat Fuß fassen können. Ein rein mechanisch-physikalischer Zerfall ist aber bei unseren Innerwürmböden bereits durchschritten. Wegen der kräftigen Braunfärbung, der Entkalkung und Trichterbildung kann keine arktische Frosterde, wegen mangelnder Eisbodenstrukturen kann auch kein eisrandnah-periglazialer Boden in Frage kommen. Für reinen Tundra-Boden erscheint die chemische Verwitterung zu stark, die Humuswirkung zu gering. Mit Steppen- und Buschvegetation, in der sich jedoch kein Lößstaub sammelte, wird man auf den durchlässigen, trockenen Schottern wohl rechnen müssen. In Lösung gegangene Eisenverbindungen konnten in dem noch kalkführenden Boden ausgefällt werden. Ein B-Horizont hat sich noch nicht gebildet. Die kaltgemäßigten, klimatisch-biologischen Bedingungen von Podsolböden oder gar von Braunerde waren nicht gegeben. Immerhin ist der Kalkgehalt beträchtlich vermindert und trat eine erhebliche Stoffwanderung nach unten ein.

Danach würde unser Innerwürmboden vielleicht am ehesten dem Bodentyp des „Braunen Rankers“ entsprechen wie ihn W. L. Kubiena (1953, 209) a us s uba r ktischem Klima beschreibt. Als Bildungszeit wird man mehrere Jahrtaus e nde annehmen müssen. In dieser Zeit war der Eisrand ohne Zweifel stark ins Gebirge zurückgeschmolzen, wie Abb. 4 angedeutet hat.

\section{Die Jungwürm-Moräne}

legte sich, wie mehrfach betont wurde, unmittelbar auf den Innerwürmboden oder, nach dessen Beseitigung, auf den Murnauer Schotter selbst. Dabei enthält diese durchweg als Grundmoräne ausgebildete Hangendschicht basal Linsen teils vom Schotter, 
teils vom Boden, über die sie übergriff. Die Moräne ist ein blaßbräunlichgrauer bis schwach gelblicher Geschiebemergel, senkrecht geklüftet und mit meist wenig zahlreichen, gekritzten Geschieben, welche bis über kopfgroß werden können. Geschiebe- oder Geröllansammlungen in der Moräne werden nicht oft beobachtet. Ihre Mächtigkeit, die in den Aufschlüssen immer nur wenige Meter beträgt, mag nordwärts, wo die Oberkante des Mu.Sch. absinkt, $10-20 \mathrm{~m}$ erreichen.

Teils bildet die Moräne die flachgewellte Grundmoränenlandschaft, teils geht sie in eine drumlinoide Landschaft mit vorwiegend SSO-NNW streichenden Kurzrücken über, die zu echten Drumlins werden können. Die Moräne kann auch übergehen in ähnlich geformte oder etwas quer liegende, kurzwallartige Kiesmoränen oder Schotter und Sande der spätwürmischen Rückzugszeit. Nur selten schwillt die Jungwürmserie zu einer solchen Mächtigkeit von 15-30 m an, daß ihr Relief die Ebenheit des darunter durchziehenden Mu.Sch. auslöscht.

Anscheinend recht einheitlich, im Verhältnis schnell und machtvoll erfolgte der Hauptvorstoß des Jungwürm-Eises durch das Alpenvorland bis zu den äußersten Würmendmoränen. Nach der Drumlinisierung großer, beweglicher Diluvialmassen im Eberfinger Drumlinfeld bildeten die Hangend-Sedimente eine wechselvolle Rückzugsgeschichtẹ des letzten Würmeises ab.

\section{Andere Anzeichen für eine Wärmeschwankung zur Innerwürmzeit}

In vorliegender Arbeit sollte zunächst einmal allein für den Bereich des LoisachAmmerseegletschers durch die Mitteilungen über den Innerwürmboden und seine Lage im Würmsystem der Nachweis einer Zweigliederung der Würmzeit geführt werden. Dieses Würminterstadial setzt jedoch eine bedeutende Klimaschwankung voraus, welche auch in den anderen Gletschergebieten des Alpenvorlandes ihre Spuren hinterlassen haben dürfte. Entsprechende Beobachtungen von P. BECK bei Thun und von J. KNAUER vom Rheingletscher wurden erwähnt. Für den Illergletscher fällt auf die pedologischen Beobachtungen über I. Schatfer's Fellheim-Nersinger W I-Terrasse durch K. BRunNACKER $(1953,113-130)$ jetzt ein neues Licht. Hier wurde zwar weithin der "Auelehm“ als sandig-lehmige Deckschicht beobachtet, jedoch unter dem Löß kein Verwitterungsboden. Es ist aber nicht von der Hand zu weisen, daß jener Auelehm nichts anderes darstellt als unseren hier fluviatil, vielleicht auch äolisch, ein wenig umgelagerter Innerwürmboden. Er führt verwitterte, aber nicht ganz zerfallene Gerölle und dürfte in der nachfolgenden, spätwürmischen Tjälezeit noch periglaziale Bewegungen mitgemacht haben. $\mathrm{Zu}$ dieser $\mathrm{Zeit}$ wird auch der ausgeblasene Lößstaub dort zur Ansammlung gekommen sein, wo hierfür eine gewisse Kaltsteppen-Vegetation die Möglichkeit bot. Auffallend ist auch die erhebliche bis $1 \mathrm{~m}$ mächtige Verwitterungsrinde an Stellen, an denen die spätere Verwitterung noch bis auf den W I-Schotter hinabreichte. Vielleicht ergibt eine genaue Untersuchung an günstigen Aufschlüssen, daß hier auch die Innerwürmverwitterung mitgewirkt hatte.

Einen ersten, einwandfreien Verwitterungsboden-Nachweis fand ich im Inngletscherbereich. Frau Dr. E. EBERs, der ich die Böden auf dem Murnauer Schotter gezeigt hatte, teilte mir freundlichst mit, daß auf dem Altwürmschotter nö. Rosenheim in einer Kiesgrube ebenfalls ein Boden zu finden sei. Bei gemeinsamer Begehung in Kiesgruben des allgemein als altwürmisch angesehenen Schotters (C. 'Troll 1924) am westlichen Inntalrande bei Rott a. I. konnte ich auf dem an Kristallin reichen und über $15 \mathrm{~m}$ aufgeschlossenen Kies unter bis 2,5 m mächtiger Grundmoräne des Jungwürms einen bis $1 / 2 \mathrm{~m}$ starken, sand- und kiesreichen Verwitterungslehm nachweisen. Die chemische Verwitterung des mit verdünnter Salzsäure nicht brausenden Bodens ist auffallend kräftiger, als sie der Boden auf dem Murnauer Schotter zeigt. Die in ihm liegenden Gerölle sind zum 
Teil weich und mürb, auch ist die Bodenfarbe mehr dunkelkreßbraun. Im Gegensatz zu dem typischen letztinterglazialen Blutlehmboden sind aber die Gerölle in dem darunterliegenden Schotter nicht verwittert. Auch bei Rott schneidet die Grundmoräne basal glatt hinweg über den Verwitterungsboden, der offenbar auch innerwürmisch ist.

Ein Diluvialschotter ist bekanntlich noch kein Nachweis für eine langdauernde, wärmere und eisfreie Zeit in unserem Alpenvorland. Der L a u f e s c hot te r kann zwar wohl verglichen werden mit dem Murnauer Schotter. Weil auf ersterem jedoch noch kein alter Verwitterungsboden gefunden worden ist, so entfiel für uns die Möglichkeit, statt unserer eisfreien „Innerwürmzeit“ den Begriff der alten A. Penck'schen „Laufenschwankung“ wieder aufzunehmen. -

Unsere durch weitere Funde ausgedehnterer Altböden des Jungdiluviums angeregten Untersuchungen werden fortgesetzt.

\section{Lit eratur}

Aigner, D.: Das Murnauer Diluvium. - Mitt, geogr. Ges. München 8, 1913.

BRUNNACKER, K.: Die bodenkundlichen Verhältnisse der würmeiszeitlichen Schotterfluren im Illergebiet. - Geol. Bavarica 18, S. 113-130, München 1953.

Büdel, J.: Die Klimaphasen der Würmeiszeit. - Die Naturwissenschaften 37, 1950.

BüDEL, J.: Die Klimazonen des Eiszeitalters. - Eiszeitalter und Gegenwart 1, S. 16, 1951.

DEHM, R.: Ein Waldelephanten-Vorkommen in zwischeneiszeitlichen Ablagerungen am Alpenrand. - Bayer. Vorgeschichtsblätter 14, S. 27, 1937.

EberL, B.: Zur Gliederung und Zeitrechnung des alpinen Glazials. - Z. deutsch. geol. Ges. 80, Mon.-Ber. S. 107-117, 1928. - - Die Eiszeitenfolge im nördlichen Alpenvorlande. Verlag B. Filser, Augsburg 1930.

Ebers, E.: Die bisherigen Ergebnisse der Drumlinforschung. - N.Jb.Min. B.-Bd. 53, B. S. 153270, 1925. - - Das Eberfinger Drumlinfeld. - Geognost. Jahreshefte 39, S. 47-85, München 1926. - - Zur Entstehung der Drumlins als Stromlinienkörper. - N. Jb. f. Min. B.-Bd. 78, B. S. 200-240, 1937.

Graul, H.: Zur Gliederung der Würmeiszeit im Illergebiet . - Geologica Bavarica 18, S. 13-48, München 1953.

Klebelsberg, R. von: Glazialgeolog. Notizen vom bayer. Alpenrand III, IV. - Zeitschr. f. Gletscherkunde 8, S. 243-262, 1914. - - Von der alpinen „Schlußvereisung“. - Ebenda 28, S. 60-66, 1942.

KNAUER, J.: Die Schieferkohle von Großweil und Ohlstadt. In „Die jüngeren Braunkohlen“, Herausgeg. v. Bayer. Oberbergamt München, S. 52-58, 1922. - - Glazialgeologische Ergebnisse aus dem Isargletschergebiet. - Z. deutsch. geol. Ges. 80, M.-Ber. S. 294-303, 1928. - - Die Ablagerungen der älteren Würmeiszeit (Vorrückungsphase) im süddeutschen und norddeutschen Vereisungsgebiet. - Abh. Geol. Landesunters. Heft 21, München 1935. - - Widerlegung der Einwendungen C. Troll's gegen die Vorrückungsphase der Würm-Eiszeit. - Mitt. geograph. Ges. München 30, 1937. - - Zur Theorie der „überfahrenen“ Würm-Endmoränen. - Mitt. Reichsstelle f. Bodenforschung, Zweigstelle München, Heft 3\%, 1942.

Koenne, W. \& NikLAS, H.: Erläuterungen zu Blatt Ampfing. - Geognost. Abt. Oberbergamt München 1916.

Kraus, E.: Der Blutlehm auf der süddeutschen Niederterrasse als Rest des postglazialen Klimaoptimums. - Geognost. Jahreshefte 34, München 1921.

Kubiena, W. L.: Bestimmungsbuch und Systematik der Böden Europas, 892 S. Verlag F. Enke, Stuttgart 1953.

Micheler, A.: Verwitterungshorizont der Würm I-Phase bei Ob im Wertach-Gletschergebiet. Bericht naturf. Ges. Augsburg 1948.

Penck, A. \& Brueckner, E.: Die Alpen im Eiszeitalter. - Leipzig 1909.

PENCK, A.: Ablagerungen und Schichtstörungen der letzten Interglazialzeit in den nördlichen Alpen. - S.-Ber. preuß. Akad. d. Wiss. 20, 1922.

Rathjens, C.: Ueber die Zweiteilung der Würmeiszeit im nördlichen Alpenvorland. - Peterm. geograph. Mitteil. 95, S. 89-97. Gotha 1951.

ReIch, H.: Die Vegetationsentwicklung der Interglaziale von Großweil-Ohlstadt und Pfefferbichl im Bayer. Alpenvorland. - Flora, Allg. Botan. Zeitung 140, S. 386-443, G. Fischer, Jena 1953. 
RothPLEtz, A.: Die Osterseen und der Isar-Vorlandgletscher. - Mitteil. geograph. Ges. München 12, Heft 2, 216 S. München 1917.

Schaefer, I.: Die Würmeiszeit im Alpenvorland zwischen Riß und Günz. - Abh. d. Naturk.und Tierg.-Vereins f. Schwaben, H. II, Geol.-pal. Reihe, 1. Heft Augsburg 1940. - Ueber methodische Fragen der Eiszeitforschung im Alpenvorland. - Z. deutsch. geol. Ges. 102, S. 297-310, Hannover 1951. - - Zur Gliederung der Würmeiszeit im Illergebiet. - Geol. Bavarica 18, 49-112, München 1953.

Sснӧnhals, E.: Uber fossile Böden im nichtvereisten Gebiet. - Eiszeitalter und Gegenwart 1, S. $109,1951$.

Schuster, J.: Paläobotanische Notizen aus Bayern. - Ber. bayer. botan. Ges. 12, I, S. 57-62, 1909.

Simon, L.: Kl. Beob. am Laufenschotter usw. - Abh. geol. Landesunters. bayr. Oberbergamt 18, 53-57, 1935.

TroLl, K.: Der diluviale Inn- und Chiemseegletscher. - Forsch. zur deutschen Landeskunde. 121 S. Stuttgart 1924. - - Die Rückzugsstadien der Würmeiszeit im nördlichen Vorland der Alpen. - Mitt. geograph. Ges. München 18, 1925. - - Die Eiszeitenfolge im nördlichen Alpenvorland. - Mitt. geograph. Ges. München 1931, 215-226. - - Die sogenannte Vorrückungsphase der Würmeiszeit usw. - Mitt geograph. Ges. München 29, S. 1-38, 1936. - - Die jungeiszeitlichen Ablagerungen des Loisachvorlandes in Oberbayern. - Geol. Rundschau 28, S. 599-611, 1937.

Voll, G.: Zur Mechanik der Molasseverformung. - Geologica Bavarica 17, 1953.

Woldstedt, P.: Quartärforschung. Einleitende Worte. - Eiszeitalter und Gegenwart 1, 1951.

ZEIL, W.: Geologie der Alpenrandzone bei Murnau in Oberbayern. - Geologica Bavarica 20, München 1954.

ZEIL, W. \& HAGN, H.: Der Geröllbestand der jungkattischen Konglomerate im Staffelsee bei Murnau. - Geol. Jahrbuch 69, 537-598, Hannover 1954.

Zorell, F.: Neuauslotungen oberbayerischer Seen. - Mitt. geogr. Ges. München 36, 1951.

Manuskr. eingeg. 21. 5. 1954.

Anschrift des Verf.: Prof. Dr. Ernst Kraus, München-Obermenzing, Verdistr. 40. 